\title{
Note
}

\section{Comparison of Browning Colour Formation on the Surface of Fish Samples during Grilling}

\author{
Yvan Llave, Hiroki Matsuda, Mika FuKUOKa and Noboru SAKaI \\ Department of Food Science and Technology, Tokyo University of Marine Science and Technology, Konan 4-5-7, Minato-ku, \\ Tokyo 108-8477, Japan
}

Received July 4, 2013 ; Accepted October 2, 2013

A comparison of the browning of fish species grilled using far-infrared (FIR) heating was evaluated. Japanese amberjack (Seriola quinqueradiata), Japanese Spanish mackerel (Scomberomorus niphonius), salmon (Oncorhynchus masou), and red sea bream (Pagrus major) were used. Temperature and colour (CIE $L^{*}, a^{*}$, and $b^{*}$ values) of the sample surface were monitored over time. The rate of $L^{*}$ change was evaluated by treating the browning reaction as a first-order reaction. Colour changes based on $a^{*}$ and $b^{*}$ values were correlated with $L^{*}$ values using empirical equations. During browning, the trajectories of sample colour changes followed almost the same pattern, except for salmon, which was probably due to astaxanthin content. Samples with higher fat content browned faster, according to their higher frequency factor $\left(k_{0}\right)$ of the browning rate. An empirical equation for $k_{0}$ prediction based on sample fat content was obtained, giving fairly good approximations to measured values.

Keywords: colour, fish species, browning, kinetic analysis, far-infrared radiation.

\section{Introduction}

Consumers often assess the initial quality of a product by its colour and appearance, and colour serves as an indicator of proper food preparation. This is especially important when the selected heating process involves high temperatures, as in the case of infrared radiation grilling.

The grilling of fish involves a phase change from liquid water to vapour. An evaporation front exists that divides the body of the food into two regions: the outer crust and the internal core (Wang and Sun, 2006). During grilling, when the surface temperature has reached $100^{\circ} \mathrm{C}$, the evaporation zone begins to move toward the centre of the product and crust formation is initiated, which decreases the heat conductivity by acting as an insulator (Quaglia and Bucarelli, 2001). Several studies have analysed the internal core region. Garcia-Arias et al. (2003) reported that cooking induces water loss in fish, which, in most cases, increases its lipid and protein contents (on a dry-matter basis) and only some fat is lost in the case of high-fat fish. Similar results were observed by Gall et al. (1983) in broiled oily fish (mackerel) but not in other lower fat fish species (grouper and red snapper). On the other hand, a few studies have focused on the outer crust region. Wang and Sun (2006) reported that the crust layer increases in both thickness and browning colour formation as the grilling process proceeds. The latter region was taken in consideration in the present study because crust layer formation at the upper surface has an impact on grilled fish appearance.

Thus, because "we also eat with our eyes," the significance of browning, a Maillard-type reaction, in consumer acceptance is obvious. The chemistry underlying the Maillard reaction is very complex; therefore, it is difficult to identify the elementary reaction and obtain the rate constant of an individual reaction. Nakamura et al. (2011) and Matsuda et al. (2013) modelled browning formation according to alterations in colour intensity and did not directly involve chemical compounds. Nakamura et al. (2011) analysed 
the browning of red sea bream during grilling according to the relationships among colour, sample surface temperature, and grilling time. They proposed a model that enables the prediction of $L^{*}$ value (fish surface colour lightness) from the surface temperature history, as well as $a^{*}$ and $b^{*}$ values (fish surface colour position on red/green and blue/yellow axes, respectively) from empirically developed equations obtained using nearinfrared radiation (NIR) heating. Matsuda et al. (2013) analysed the browning of red sea bream grilled using far-infrared radiation (FIR) and superheated steam (SHS) heating, in addition to NIR heating. The results confirmed that the kinetic model developed by Nakamura et al. (2011) can be applied toward the browning formation of fish during grilling independent of the heat transfer mode. However, analyses of the browning formation rate at the crust surface layer of various fish species during grilling in the context of intrinsic chemical composition are scarce. Thus, the present study aims to clarify this.

In contrast to warm-blooded meat, the factors that influence Maillard reaction formation are somewhat different in fish or fishery products. Variations in the chemical composition of fish are closely related to feed intake, migratory swimming, and sexual changes related to spawning. The lipid fraction is widely recognized as the component exhibiting the greatest variability. It is well known that in many fish species, the sum of the crude fat and moisture contents of muscle tissue is almost constant despite variation in seasonal fat content (Llave et al., 2012; Mohan et al., 2008; Oehlenschläger and Rehbein, 2009). Moreover, the carbohydrate and ash contents are low and do not exhibit significant seasonal changes (Hatae and Kasai, 2003; Wada, 2002). Thus, the remaining contents, which consist mostly of proteins, are easily calculated as the difference from the other chemical compounds. The chemical composition data of fish could facilitate understanding the surface colour changes during FIR grilling as a function of their crude fat or moisture content. In the present study, we evaluated the surface colour changes of several fish species during FIR grilling, and its practical estimation using crude fat content.

\section{Theoretical}

Kinetic study of browning reaction during grilling The browning kinetics theory used in this study to determine the activation energy $\left(E_{\mathrm{a}}\right)$ and frequency factor $\left(k_{0}\right)$ of the calculated rate of $L^{*}{ }_{\mathrm{c}}$ reduction of the samples was described in detail in our previous reports (Matsuda et al., 2013; Nakamura et al., 2011). Therefore, browning was modelled according to the change in colour intensity and did not directly involve chemical compounds. To determine the calculated $a^{*}{ }_{\mathrm{c}}$ and $b^{*}{ }_{\mathrm{c}}$ values, based on changes in $L^{*}$ c value, we employed the empirical equations reported in our previous reports.

\section{Materials and Methods}

Materials In this study, the light muscle of Japanese amberjack adults and alevin (Seriola quinqueradiata), Japanese Spanish mackerel (Scomberomorus niphonius), and salmon (Oncorhynchus masou) was used. Additionally, the results of red sea bream (Pagrus major) previously reported in Matsuda et al. (2013) were included for comparison purposes since the theoretical model for colour estimation used here was developed with this species. These fish species were chosen because they are commonly used for grilling. They were purchased from a fish market on the day of the experiment and were in all cases under rigor mortis. The skin and bones were removed, and the ordinary muscle of the fillets was cut into $5 \times 6 \times 2-\mathrm{cm}$ pieces for all experiments. Pieces from the same fish were used to complete a single experimental run. The samples were wrapped in plastic film and were refrigerated $\left(5^{\circ} \mathrm{C}\right)$ until use, no more than $30 \mathrm{~min}$.

Moisture and crude fat contents The moisture and crude fat contents of fish samples were quantified. Samples were ground with a mortar and pestle. Crude fat content was determined by the Bligh \& Dyer method using a 10-g portion of the ground sample. Moisture content was determined on a wet basis by drying a $5-\mathrm{g}$ portion of the ground sample at $40^{\circ} \mathrm{C}$ to a constant weight by the gravimetric reduced pressure method at $0.09 \mathrm{MPa}$. The results are expressed as the mean value \pm SD of five replicates obtained from each of the five fish samples.

Experimental conditions The FIR heater $(100 \mathrm{~V} / 750 \mathrm{~W}$; electric ceramic plate heater PLC-328, Noritake Co., Aichi, Japan) was $12 \mathrm{~cm}^{2}$, and the infrared energy radiated downward from the heater. The samples were positioned approximately $8 \mathrm{~cm}$ below the heat source on an electronic balance. The FIR heater was preheated $30 \mathrm{~min}$ prior to the start of the experiment, and the radiation energy was measured three times during the grilling process. The FIR heater was adjusted to $400^{\circ} \mathrm{C}$, and the temperature at the sample point was verified as $200 \pm 1.5^{\circ} \mathrm{C}$ during the entire grilling process. The radiation energy, measured using a radiation sensor (RF30; Captec, Villeneuve d'Ascq, France) at the same sample position, was $2.7 \times 10^{4} \mathrm{~W} \mathrm{~m}^{-2}$ (with a standard deviation of $2.2 \%$ ). For further details of the FIR experimental grilling apparatus refer to Matsuda et al. (2013).

Surface temperature measurement The surface temperature of samples was measured using a K-type thermocouple $(\varphi=$ $0.5 \mathrm{~mm}$ ). A single measured profile was collected from each run using the sample with longest grilling time. A personal computer, a datalogger (Thermodac 5001A; Eto Denki Co., Tokyo, Japan), and software (Thermodac-E/Ef 2.6; Eto Denki Co.) were used to collect the temperature data. The accuracy of the surface temperature profiles collected using K-type thermocouples was verified by comparison with profiles collected with IR sensors. For details refer to Matsuda et al. (2013).

Colour measurement Changes in the colour values of the fish surface were measured using the CIE $L^{*}, a^{*}$, and $b^{*}$ system at the same position as the surface temperature measurements, with a spectrophotometric colour difference meter (NF333; Nippon 
Denshoku Industries Co., Ltd., Tokyo, Japan). The $L^{*}, a^{*}$, and $b^{*}$ values were measured using a D65 light source with a viewing field angle of $2^{\circ}$. Sampling of the grilled fishes was conducted at $0,2,4$, 6,8 , and $10 \mathrm{~min}$. Results are expressed as the mean value $\pm \mathrm{SD}$ of five replicates obtained from the surface centre in each of the five fish samples.

Statistical evaluation Composition data was analysed by a one-way ANOVA combined with Turkey's pairwise comparison test, using the Systat statistical software (version 3.5; Systat Software Inc., IL, USA).

\section{Results and Discussion}

Crude fat and moisture contents Figure 1 shows the mean values for the crude fat and moisture contents of the fish muscle samples. The sum of both contents was largely constant at 0.804 $\pm 0.007 \mathrm{~kg} / \mathrm{kg}$ muscle irrespective of the fish species. There was a negative linear correlation between crude fat and moisture contents in the muscle of the fish species examined herein and a standard deviation of $\pm 0.5 \%$ was present in all cases. The inverse relationship between water and fat contents has been described in various fish species, a factor that is highly dependent on the catch season (Garcia-Arias et al., 2003; Llave et al., 2012; Mohan et al., 2008).

Surface colour changes of fish samples Figure 2 shows the colour change in red sea bream, Japanese amberjack, and salmon during FIR grilling. Samples of similar size and weight were used for this experiment; sample colour was measured and photographs were taken at constant time intervals. Differences in the browning formation of these 3 fish species were observed. Japanese amberjack and salmon exhibited homogenous colour formation and a higher surface browning rate, probably due to the high crude fat contents $(13.8 \pm 0.24 \%$ and $10.6 \pm 0.19 \%$, respectively) of their muscle; in contrast, red sea bream had a low fat content $(2.0$ $\pm 0.14 \%$ ), resulting in heterogeneous surface colour formation. Grilling causes free water release and water evaporation from the muscle. This results in decreased surface moisture levels, a factor which is influenced by the initial moisture content of the sample. This dynamic process changes the local temperature and could be the reason for the presence of black spots at surfaces carbonized locally. This effect was less noticeable in samples with a high fat content, i.e., in the case of Japanese amberjack or salmon.

According to Nakamura et al. (2011), colour changes during grilling involve 4 steps: (1) protein denaturation, (2) water evaporation, (3) browning reaction, and (4) carbonization reaction. Since the colour change caused by the browning reaction occurs at temperatures exceeding $110^{\circ} \mathrm{C}$ (Matsuda et al., 2013; Nakamura et al., 2011), data measured after protein denaturation (at temperatures at this level) were plotted in Fig. 3A-C to compare the trajectory of colour changes during grilling-induced browning formation.

Two-dimensional projection drawings of the $L^{*}{ }_{\mathrm{m}}-a_{\mathrm{m}}^{*}, L_{\mathrm{m}}^{*}-b^{*}{ }_{\mathrm{m}}$, and $b_{\mathrm{m}}^{*}-a_{\mathrm{m}}^{*}$ planes are shown in these figures, and correlations between the measured colour values are plotted with the calculated colour values (NIR results of red sea bream reported by Nakamura et al., 2011 are shown as solid black lines). The plotted data of the fish samples follow almost the same trajectories as the calculated values, even though FIR grilling was used instead of NIR grilling, which was employed by Nakamura et al. (2011) in developing the kinetic browning formation model.

The results were concordant regardless of fat content, except for salmon. In salmon, pinkish-orange muscle was initially observed, and the pattern of browning formation differed from that of other fish species. The different trajectory detected for salmon, especially regarding $a_{\mathrm{m}}^{*}$ values, can probably be attributed to the astaxanthin content of muscle. Salmon muscle colour changes during thermal processing due to myoglobin denaturation and oxidization of carotenoid pigments; thus, the colour changes from pinkish-orange to pale pink (Haard, 1992). The typical pinkishorange colour of salmon strongly affects colour change behaviour during the browning reaction, and is dependent on the pigment concentration of the muscle (Skreede and Storebakken, 1986).

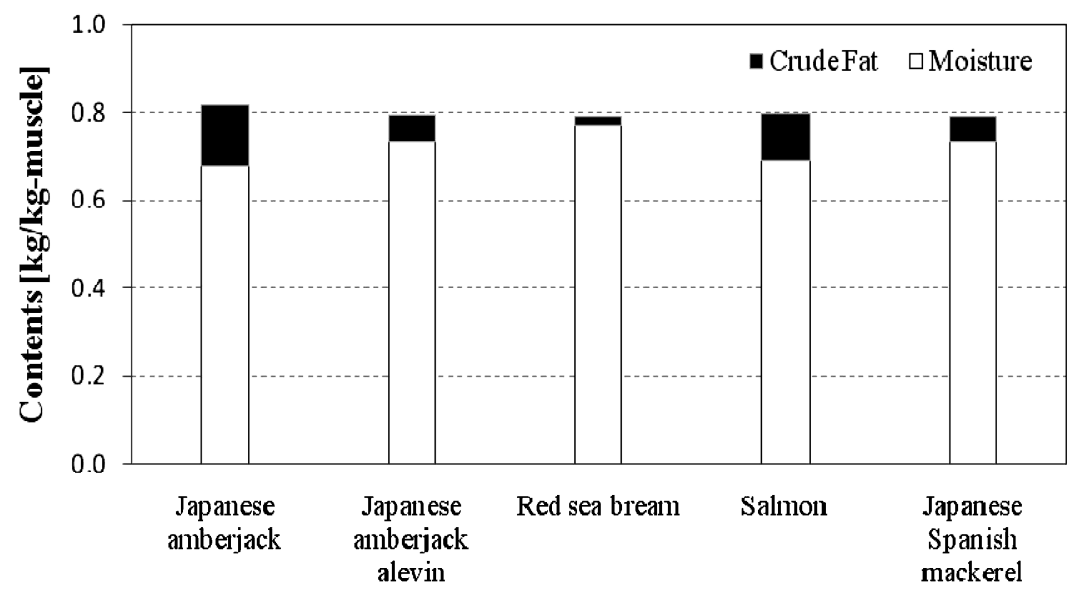

Fish species

Fig. 1. Moisture and crude fat contents of the fish species examined in this study. 


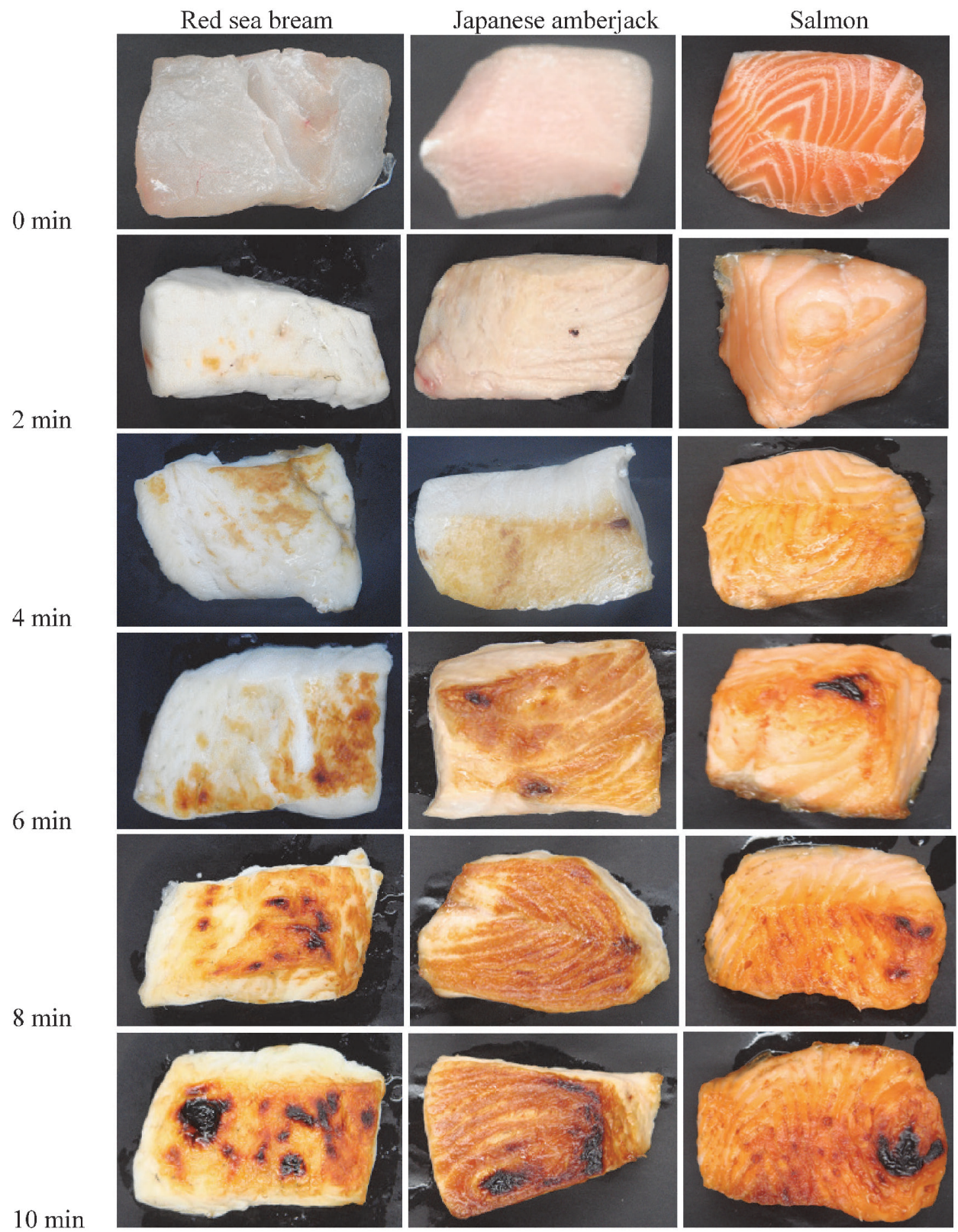

Fig. 2. Comparison of the surface colour changes of red sea bream, Japanese amberjack, and salmon during FIR grilling.

Kong et al. (2007) and Skreede and Storebakken (1986) reported that the initial pigment concentration in salmon muscle is affected by feed intake; this factor varies by sample and species, making it difficult to control and therefore model. Salmon contains high levels of polyunsaturated fatty acids that are prone to oxidation and colour alteration during heating. Fat composition has an influence on colour formation during grilling, and this influence is proportional to the total fat content of the sample (Garcia-Arias et al., 2003; Sohn et al., 2005). Since the trajectory in colour space of salmon differed from those of other fish species, a different kinetics model is required for predicting the browning formation in fish with pigmented or dark muscle.

Estimation of colour changes in fish during grilling The measured data of surface colour changes together with the calculated values $\left(L^{*}, a^{*}\right.$, and $b^{*}$ ) of three fish samples under
FIR grilling are shown in Fig. 4A-C. The model was not a good predictor of salmon; thus, these results were not considered in this section. The results showed that the colour change trend was similar in all fish species. In these samples, the colour was white and bright up to $95 \sim 100^{\circ} \mathrm{C}$, at which point the colour began to change as a result of protein denaturation; this temperature range was also the point at which $L^{*}{ }_{\mathrm{m}}$ peaked. Above this temperature, $L^{*}{ }_{\mathrm{m}}$ decreased gradually as the water evaporated. Simultaneously, $a^{*}{ }_{\mathrm{m}}$ and $b_{\mathrm{m}}^{*}$ increased slightly as a result of the browning reaction. Finally, when the surface temperature was close to $150^{\circ} \mathrm{C}$, the samples began to darken, $a_{\mathrm{m}}^{*}$ peaked, and $L_{\mathrm{m}}^{*}$ was approximately 30. This was considered the starting point of the carbonization step. Similar results were reported by Nakamura et al. (2011) using NIR heating and Matsuda et al. (2013) using FIR and SHS heating of red sea bream. Beyond this point, $L^{*}{ }_{\mathrm{m}}, a^{*}{ }_{\mathrm{m}}$, and $b^{*}{ }_{\mathrm{m}}$ decreased 

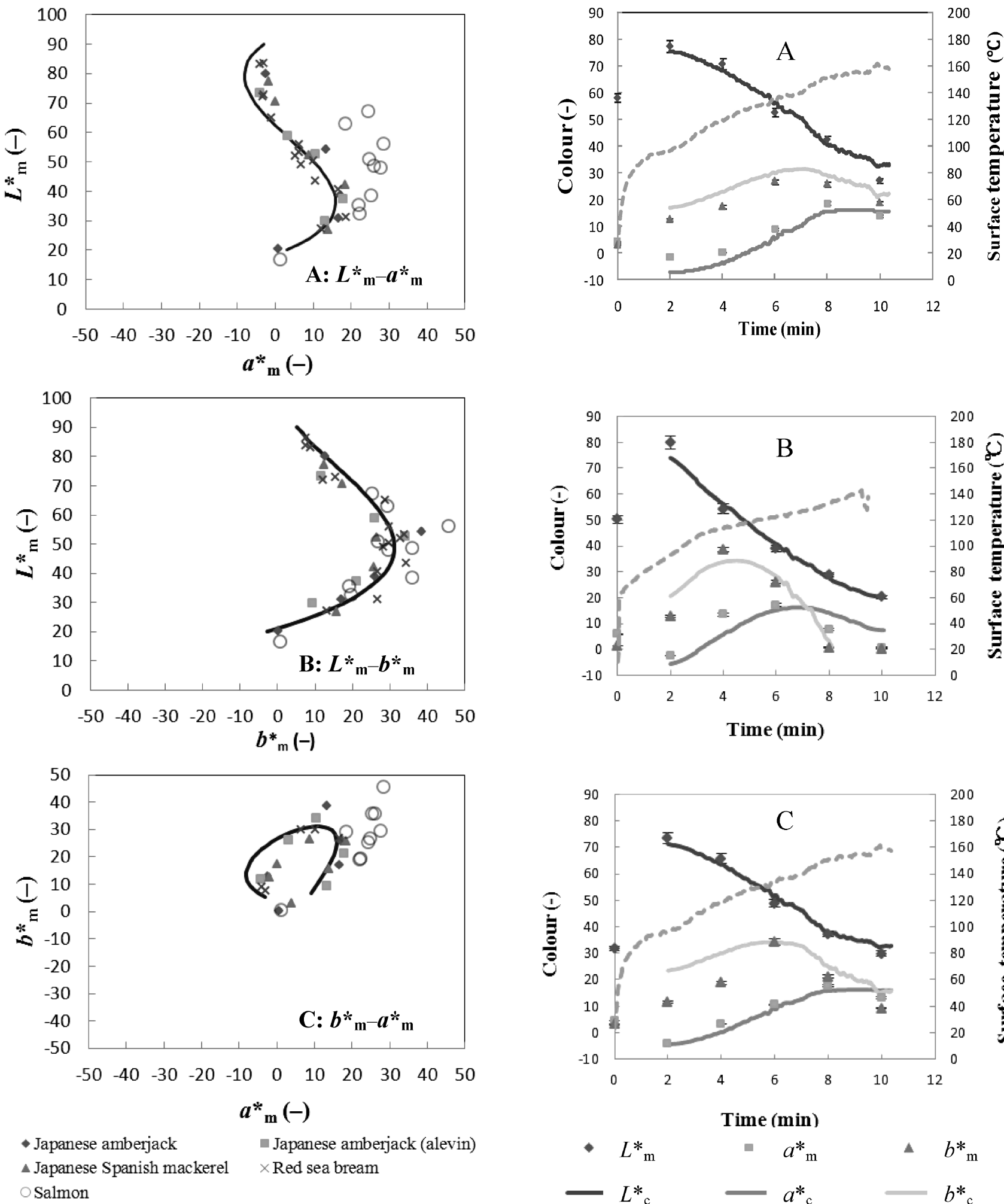

Fig. 3. Relationships between $L^{*}{ }_{\mathrm{m}}$ and $a^{*}{ }_{\mathrm{m}}(\mathrm{A}), L^{*}{ }_{\mathrm{m}}$ and $b^{*}{ }_{\mathrm{m}}(\mathrm{B})$, and $b^{*}{ }_{\mathrm{m}}$ and $a^{*}{ }_{\mathrm{m}}(\mathrm{C})$. Solid lines represent the correlation with NIR calculated values reported by Nakamura et al. (2011).

as the surface temperature continued to rise. Thus, although the kinetics model used to estimate browning was developed using red sea bream, which, unlike the other species, is a white-fleshed fish with a low fat content and an initial redness value of $a_{\mathrm{m}} \approx 0$, predictions using this model were successful.

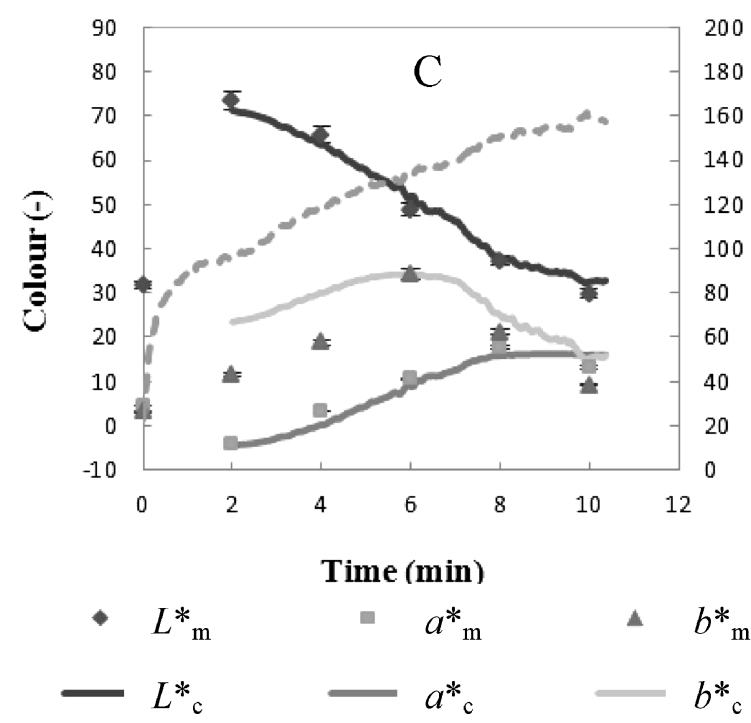

Fig. 4. Comparison of measured and calculated $L^{*}, a^{*}$, and $b^{*}$ values. A: Japanese Spanish mackerel, B: Japanese amberjack, C: Japanese amberjack alevin. Dashed lines represent the mean surface temperature profile. Bars indicate the standard deviation.

Kinetic analysis of browning reaction during grilling The kinetics parameters of the rate of $L^{*}$ c reduction in the fish species were obtained and are presented in Table 1. Results of red sea bream were inserted for comparison. There were no significant differences between fish species $(p>0.05)$ with respect to 
Table 1. Comparison of kinetics parameters, $E_{\mathrm{a}}$ and $k_{0}$, in the rate of $L^{*}$ value reduction of the fish species during grilling using FIR heating.

\begin{tabular}{ccccc}
\hline $\begin{array}{c}\text { Kinetics } \\
\text { parameters }\end{array}$ & $\begin{array}{c}\text { Japanese } \\
\text { amberjack }\end{array}$ & $\begin{array}{c}\text { Japanese } \\
\text { amberjack } \\
\text { (alevin) }\end{array}$ & $\begin{array}{c}\text { Japanese } \\
\text { Spanish } \\
\text { mackerel }\end{array}$ & $\begin{array}{c}\text { Red sea } \\
\text { bream }\end{array}$ \\
\hline${ }^{*} E_{\mathrm{a}}\left[\mathrm{kJ} \mathrm{mol}^{-1}\right]$ & $49.6 \pm 0.22^{\mathrm{a}}$ & $51.1 \pm 0.15^{\mathrm{a}}$ & $50.8 \pm 0.21^{\mathrm{a}}$ & $50.7 \pm 0.20^{\mathrm{a}}$ \\
${ }^{*} k_{0}\left[\mathrm{~s}^{-1}\right]$ & $9875 \pm 62^{\mathrm{a}}$ & $6721 \pm 39^{\mathrm{b}}$ & $6347 \pm 52^{\mathrm{c}}$ & $4759 \pm 51^{\mathrm{d}}$ \\
\hline
\end{tabular}

$E_{\mathrm{a}}$ : activation energy; $k_{0}$ : frequency factor; "Mean \pm standard deviation of the kinetics parameter values $(n=3)$; values with different super scripts within a line are significantly different $(p<0.05)$.

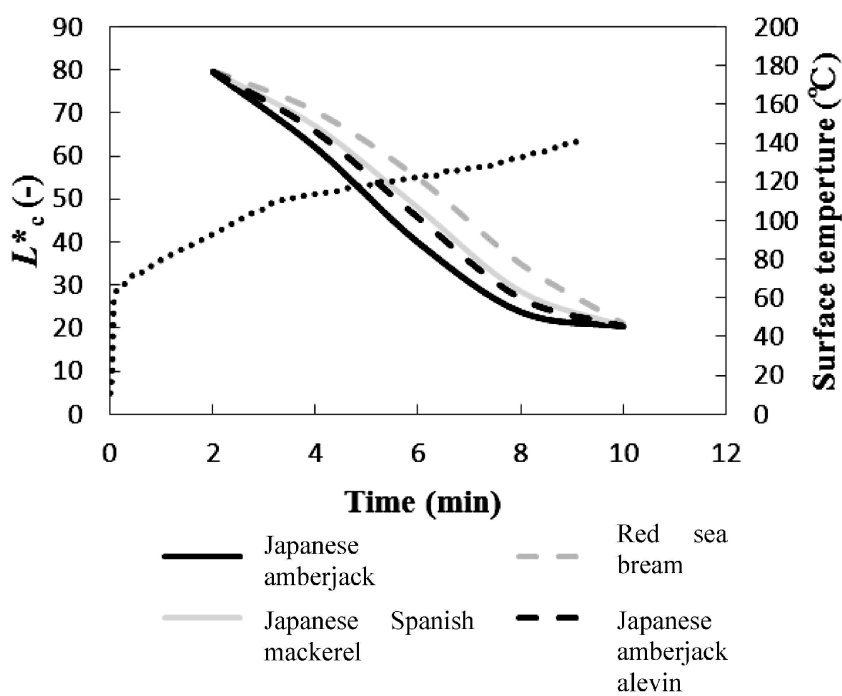

Fig. 5. Comparison of calculated $L^{*}{ }_{\mathrm{c}}$ values of the fish species using identical $E_{\mathrm{a}}\left(51.0 \mathrm{~kJ} \mathrm{~mol}^{-1}\right)$ and surface temperatures (shown in dotted black line).

activation energy, $E_{\mathrm{a}}$. Meanwhile, the frequency factor $\left(k_{0}\right)$ value differed significantly $(p<0.05)$ between all fish species.

Since the $\left(E_{\mathrm{a}}\right)_{\mathrm{n}}$ values $(n=1-4)$ of the 4 fish species were quite similar, the same $E_{\mathrm{a}}$ value $\left(51.0 \mathrm{~kJ} \mathrm{~mol}^{-1}\right)$ was assumed for all of them. Using this $E_{\mathrm{a}}$ value, the frequency factor, $k_{0}$, was recalculated using the method described by Nakamura et al. (2011). The goal was to analyse the effect of $k_{0}$ values on the rate of $L^{*}{ }_{\mathrm{c}}$ reduction. The calculated $k_{0}$ values were: $9763 \mathrm{~s}^{-1}, 6892 \mathrm{~s}^{-1}, 6131 \mathrm{~s}^{-1}$, and $4225 \mathrm{~s}^{-1}$, respectively. Therefore, using these recalculated values, the calculated $L^{*}{ }_{\mathrm{c}}$ value profiles of the fish species were compared under the same surface temperature (using the surface temperature of red sea bream) and are presented in Fig. 5.

The rate of $L^{*}{ }_{\mathrm{c}}$ reduction was highly dependent on $k_{0}$, which differed greatly between fish species $(p<0.05)$. These results are attributable to differences in crude fat contents (Fig. 1). Thus, the higher the fat content, the higher the rate of $L^{*}{ }_{\mathrm{c}}$ reduction. This is reasonable because the browning of samples with a high fat content is more intense than those with a low fat content, i.e., in the case of red sea bream (Fig. 2). The relationship between mean $k_{0}$ value and crude fat content is well described by Eq. 1, the coefficient of determination $\left(R^{2}\right)$ being 0.9752 :

$$
k_{0}=\left[\left(4.6 \times 10^{4} \times X_{\mathrm{F}}\right)+\left(3.5 \times 10^{3}\right)\right]
$$

where $X_{\mathrm{F}}$ is the crude fat content $\left(0.02 \leq X_{\mathrm{F}} \leq 0.14\right)$. Thus, the $k_{0}$ values can be calculated from the crude fat content of the samples using Eq. 1.

The accuracy of $k_{0}$ value estimation, estimated from the data (results from Table 1) and the values predicted using Eq. 1, showed a correlation coefficient of 0.9982 with $X_{\mathrm{F}} \leq 0.14$. A similar estimation can be conducted using moisture content instead of crude fat content according to the relationship between moisture and crude fat contents presented above.

The mean values of $L^{*}{ }_{\mathrm{m}}, a^{*}{ }_{\mathrm{m}}$, and $b^{*}{ }_{\mathrm{m}}$ and the calculated values using $k_{0}$ values obtained from Eq. 1 were in good agreement in the three samples (Fig. 4A-C). On the other hand, the significant differences $(p<0.05)$ observed in colour changes (Fig. 4B-C) and $k_{0}$ values (Table 1) between Japanese amberjack adults and alevin were probably also due to differences in fat content $(13.8 \pm 0.24 \%$ and $8.2 \pm 0.22 \% \mathrm{w} / \mathrm{w})$, respectively.

\section{Conclusions}

Precise knowledge of the dynamics of colour changes during the grilling process is essential to determine the degree of cooking, especially at high cooking temperatures. Although the intrinsic chemical composition of fish is known to affect browning formation, there is a lack of information with respect to grilled fish. The present study, therefore, analysed colour changes in the muscle of several grilled fish species and a browning colour formation model was successfully used to estimate values. During browning, the trajectory of colour changes follows almost the same pattern under FIR grilling, regardless of sample surface temperature or fish species, with the exception of salmon. The observed differences in browning formation of salmon may be attributable to the astaxanthin content of muscle. The activation energy $\left(E_{\mathrm{a}}\right)$ of the rate of $L^{*}$ reduction was similar and independent of the fat composition of the fish. In contrast, the frequency factor $\left(k_{0}\right)$ showed significant differences between fish species and was strongly correlated to crude fat content. Further studies involving visualization of the browning formation of fish during grilling using an appropriate model is necessary.

Acknowledgements This work was supported in part by a Grantin-Aid for Scientific Research (C) from the Ministry of Education, Culture, Sports, Science and Technology of Japan (22500728). 


\section{References}

Gall, K.L., Otwell, W.S., Koburger, J.A., and Appledorf, H. (1983). Effects of four cooking methods on the proximate, mineral, and fatty acid composition of fish fillets. J. Food Sci., 48, 1068-1074.

Garcia-Arias, M.T., Alvarez Pontes, E., Garcia-Linares, M.C., GarciaFernandez, M.C., and Sanchez-Muniz, F.J. (2003). Cooking-freezingreheating (CFR) of sardine (Sardine pilchardus) fillets. Effect of different cooking and reheating procedures on the proximate and fatty acid compositions. Food Chem., 83, 349-356.

Haard, N.F. (1992). Biochemistry and chemistry of colour and colour changes in seafoods. In: "Advances in Seafood Biochemistry Composition and Quality," ed. by G.J. Flick and R.E. Martin. Technomic Publishing Company Inc., Lancester, pp. 305-360.

Hatae, K. and Kasai, M. (2003). "Tokyo Chemical literary group, 6". Tokyo Kagaku Dojin (in Japanese).

Kong, F., Tang, J., Rasco, B., and Crapo, C. (2007). Kinetics of salmon quality changes during thermal processing. J. Food Eng., 83, 510-520.

Llave, Y., Hagiwara, T., and Sakiyama, T. (2012). Effects of composition and temperature on the specific heat of Japanese anchovy (Engraulis japonicus) muscle. Jpn. J. Thermophys. Prop., 26(3), 122-127.

Matsuda, H., Llave, Y., Fukuoka, M., and Sakai, N. (2013). Color changes in fish during grilling - Influences of the heat transfer and heating medium on browning color. J. Food Eng., 116, 130-137.

Mohan, M., Ramachandran, D., Sankar, T.V., and Anandan, R. (2008).
Physicochemical characterization of muscle proteins from different regions of mackerel (Rastrelliger kanagurta). Food Chem., 106, 451-457.

Nakamura, M., Mao, W., Fukuoka, M., and Sakai, N. (2011). Analysis of the colour change in fish during the grilling process. Food Sci. Technol. Res., 17(6), 471-478.

Oehlenschläger, J. and Rehbein, H. (2009). Basic facts and figures. In: "Fishery Products: Quality, Safety and Authenticity," ed. by H. Rehbein and J. Oehlenschläger. Wiley-Blackwell, Oxford, pp. 1-18.

Quaglia, G.B. and Bucarelli, F.M. (2001). Effective process control in frying. In: "Frying. Improving quality," ed. by J.B. Rossel. CRC Press, Boca Raton, pp. 236-265.

Skreede, G. and Storebakken, T. (1986). Characteristics of colour in raw, baked and smoked wild and pre-reared Atlantic salmon. J. Food Sci., 51, 804-808.

Sohn, J.H., Taki, Y., Ushio, H., Kohata, T. Shioya, W., and Oshima, T. (2005). Lipid oxidations in ordinary and dark muscles of fish. Influence on rancid off-odor development and colour darkening of yellowtail flesh during ice storage. J. Food Sci., 70, 490-496.

Wada, S. (2002). "That's why sardines are good for the body," ed. by S. Wada. Seizando, Tokyo, pp. 55-70 (in Japanese).

Wang, L. and Sun, D.W. (2006). Heat and mass transfer in thermal food processing. In: "Thermal food processing. New technologies and quality issues,” ed. by D.-W. Sun. CRC Press, Boca Raton, pp. 35-71. 